\title{
International remittances and immigration aspects in the cases of Romania and Bulgaria in the context economic growth
}

\author{
Alina Petronela Haller ${ }^{1}$, Cristina Rodica Butnaru ${ }^{2}$ and Gina Ionela Butnaru ${ }^{3 * *}$ \\ 1 Department of Economics, Romanian Academy Branch of Iaşi + ICES, Gh. Zane, Codrescu 2, 700488 Iaşi, \\ Romania; \\ 2 Strategy social and environmental responsibility department, School of Management Sciences, University of \\ Quebec at Montreal, PO Box 8888, Downtown Branch Montreal, Quebec H3C 3p8; reteaca. \\ ${ }^{3}$ Department of Management, Marketing and Business Administration, Alexandru Ioan Cuza University of Iaşi, \\ Bulevardul Carol I 11, 700506 Iaşi, Romania; * Correspondence
}

\begin{abstract}
This work is treating a current topic, but not a new one: migration and influencing factors in the context economic growth. The migration process is analysed regarding the impact of remittances, income, expenses, and direct foreign investments on GDP/capita in the particular case of Romania and Bulgaria, European countries where migration has alarming dimensions. The regression analysis was performed with specific indicators starting with 1990, taken from the databases of the United Nations (UN), Eurostat, and World Bank (WB). The results obtained from the modelling of the migration process show that the volume of remittances significantly influences the migration level, and the level of inequalities of both countries. The level of direct investment (inflow) explains in small proportion the number of Romanian migrants in the European Union 28 (EU28), however it cannot explain this variation for Bulgaria. The conclusions of the analysis helped forming the profile of Romanian and Bulgarian migrant, similar in the causes of their decision to leave their countries, like deprivation, especially the economic one.
\end{abstract}

Keywords: immigration, UE28, remittances, economic growth, income per capita, spending per capita, foreign direct investment per capita 
